\title{
Gastric cancer diagnosed after Helicobacter pylori eradication in diabetes mellitus patients
}

\author{
Kosuke Sakitani ${ }^{1,2^{*}}$, Yoshihiro Hirata ${ }^{2}$, Nobumi Suzuki ${ }^{1}$, Satoki Shichijo ${ }^{2}$, Ayako Yanai ${ }^{1}$, Takako Serizawa ${ }^{2}$, \\ Kei Sakamoto ${ }^{1}$, Masao Akanuma', Shin Maeda ${ }^{3}$, Yutaka Yamaji ${ }^{2}$, Yasuhiko Iwamoto', Shoji Kawazu' \\ and Kazuhiko Koike ${ }^{2}$
}

\begin{abstract}
Background: Helicobacter pylori infection is the most important risk factor for gastric cancer, for which eradication therapy is commonly performed. However, gastric cancer is sometimes discovered after successful eradication of $H$. pylori. Much evidence indicates that diabetes mellitus (DM) is a risk factor for gastric cancer. The incidence and characteristics of gastric cancer diagnosed after $\mathrm{H}$. pylori eradication in DM patients remain to be determined.

Methods: We followed the clinical course of patients who underwent H. pylori eradication therapy at our institution. Endoscopy was performed before and after eradication. We compared the incidence and clinical characteristics of gastric cancer arising in DM and non-DM patients.

Results: In total, 965 patients who underwent successful eradication (518 DM and 447 non-DM patients) were followed-up for an average of 4.5 years. During the follow-up period, 21 gastric cancers were diagnosed (12 in DM patients and 9 in non-DM patients). The incidence of gastric cancer after eradication was not significantly different between DM and non-DM patients (0.485 and $0.482 \% / y e a r$, respectively). There was no significant difference in the pathology, diameter, depth, location, or treatment of gastric cancer between patients with and without DM.
\end{abstract}

Conclusion: The incidence and characteristics of gastric cancer occurring after $\mathrm{H}$. pylori eradication were comparable between DM and non-DM patients.

Keywords: Gastric cancer, Helicobacter pylori eradication, Diabetes mellitus

\section{Background}

Gastric cancer is a major cause of cancer death worldwide. Infection with Helicobacter pylori (H. pylori), first isolated by Warren and Marshall [1], together with the subsequent changes in the gastric mucosa, is the most important risk factor for gastric cancer [2-5]. Previous reports have suggested that $H$. pylori eradication reduces the incidence of gastric cancer [6-8]. Therefore, eradication therapy is now commonly performed. However, gastric cancer is occasionally discovered after successful H. pylori eradication, and investigations of the risk factors for, and characteristics of, gastric cancer after eradication have been conducted $[9,10]$.

\footnotetext{
* Correspondence: sakitani-tky@umin.ac.jp

${ }^{1}$ The Institute for Adult Diseases, Asahi Life Foundation, 2-2-6 Bakuro-cho,

Nihon-Bashi, Chuo-ku, Tokyo 113-8655, Japan

2Department of Gastroenterology, Graduate School of Medicine, The

University of Tokyo, Tokyo, Japan

Full list of author information is available at the end of the article
}

The infection-inflammation-cancer axis is widely accepted, based in part on epidemiological and basic investigations of $H$. pylori [11]. On the other hand, evidence is accumulating that diseases associated with adult lifestyle factors-e.g., diabetes mellitus (DM)-enhance the risk of malignancies, including gastric cancer [12, 13]. Thus, it is possible that the presence of DM might affect the gastric carcinogenesis such as incidence and histological characteristics of gastric cancer after H. pylori eradication.

However, few studies have examined the inhibitory effect of $H$. pylori eradication therapy on gastric cancer in DM patients. In this study, we investigated the incidence and characteristics of gastric cancer diagnosed after $H$. pylori eradication in DM patients.

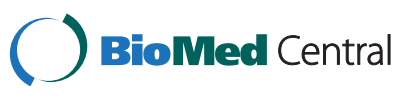

(c) 2015 Sakitani et al. Open Access This article is distributed under the terms of the Creative Commons Attribution 4.0 International License (http://creativecommons.org/licenses/by/4.0/), which permits unrestricted use, distribution, and reproduction in any medium, provided you give appropriate credit to the original author(s) and the source, provide a link to the Creative Commons license, and indicate if changes were made. The Creative Commons Public Domain Dedication waiver (http://creativecommons.org/publicdomain/zero/1.0/) applies to the data made available in this article, unless otherwise stated. 


\section{Methods \\ Patients}

To evaluate the incidence and characteristics of gastric cancer diagnosed after $H$. pylori eradication in DM patients, 991 patients who underwent successful $H$. pylori eradication therapy at our institution between January 1996 and March 2013 and were followed up for over 6 months (the follow-up period was defined as the period from the day of commencement of eradication therapy to the day of the last endoscopy performed at our institution) were analyzed retrospectively. Then, we excluded patients who met the following criteria: i) those in whom endoscopy before eradication was not conducted at our institution $(n=18)$ and ii) those with a previous history of gastrectomy $(n=8)$. Therefore, a total of 965 patients were included in the analysis.

Patients were divided into DM and non-DM groups. DM was diagnosed according to the 2010 Japan Diabetes Society (JDS) criteria [14]. The diagnoses of hypertension (HT), hyperlipidemia (HL), and hyperuricemia (HU) were based on the need for medical treatment. The study design was approved by the Ethics Committee at the Institute for Adult Diseases, Asahi Life Foundation and conformed to the Declaration of Helsinki. The patients' records were anonymized prior to analysis. Written informed consent was obtained from all participants.

\section{H. pylori eradication therapy}

H. pylori infection was defined by a positive result for at least one of the following: rapid urease test (Helicocheck, Otsuka Pharmaceuticals, Tokyo, Japan), serological testing for anti-H. pylori IgG, ${ }^{13} \mathrm{C}$-urea urea breath test, or pathological analysis by hematoxylin and eosin or Giemsa staining. Patients in whom $H$. pylori infection was confirmed underwent eradication therapy. Patients in whom eradication therapy had failed received additional treatment: the first-line regimen comprised a proton pump inhibitor (PPI), amoxicillin, and clarithromycin [15]; the second-line regimen comprised a PPI, amoxicillin, and metronidazole; and the third-line regimen comprised a PPI, amoxicillin, and sitafloxacin [16]. The success or failure of eradication therapy was determined by a ${ }^{13} \mathrm{C}$-urea breath test performed at least 4 weeks after treatment.

\section{Endoscopy}

At our institution, patients who receive eradication therapy are recommended to undergo esophagogastroduodenoscopy annually. The upper gastrointestinal endoscopies were performed by experienced endoscopists. Gastric mucosal atrophy was evaluated using the endoscopic scale described by Kimura and Takemoto [17], which has been reported to concord with the histological results [18]. Patients were classified into three groups according to their endoscopic atrophic gastritis grade: the mild (C-I and $\mathrm{C}$-II), moderate (C-III and $\mathrm{O}-\mathrm{I})$, and severe atrophic gastritis (O-II and O-III) groups.

\section{Gastric cancer determination}

Biopsy specimens were taken from the neoplastic lesion, and the final diagnosis of gastric cancer was based on the pathology results. Gastric cancers were classified pathologically according to Lauren's classification as intestinal or diffuse type [19]. A lesion identified by endoscopy prior to eradication was not counted as gastric cancer after eradication in this study.

\section{Statistical analysis}

All statistical analyses were performed using the JMP10 software (SAS Institute, Cary, NC, USA). Welch's $t$-test was used to compare the means of continuous variables. Comparisons of nominal variables were performed by $\chi^{2}$ test or Fisher's exact test, as appropriate. The incidence of gastric cancer in patients with and without DM was evaluated using the Kaplan-Meier method, and the statistical significance of the differences was evaluated by log-rank test. The diagnosis of gastric cancer was the primary endpoint, and data were censored at the last endoscopy. The risk of gastric cancer after eradication was assessed using Cox's proportional-hazards model. Since no gastric cancer was detected in the mild atrophic gastritis group, this group served as the control. Odds ratios (OR) with $95 \%$ confidence intervals (CI) were used as a measure of association and were adjusted using unconditional logistic regression models. A two-sided $p$-value of less than 0.05 was considered to indicate statistical significance.

\section{Results}

\section{Baseline characteristics of the patients}

The baseline characteristics of the patients are provided in Table 1. In total, 965 patients (729 males and 236 females, mean age 62.9 years, and mean body mass index (BMI) $23.2 \mathrm{~kg} / \mathrm{m}^{2}$ ) underwent successful $H$. pylori eradication therapy as the first-, second-, and third-line regimens in $782(81.0 \%), 178$ (18.4 \%), and 5 (0.52\%) patients, respectively. The 965 patients comprised 518 DM patients (13 type $1 \mathrm{DM}$ and 505 type $2 \mathrm{DM}$ patients) and 447 nonDM patients. Patients were followed-up for up to 16.2 years (mean 4.5 years). In terms of the endoscopic atrophic gastritis grade, 173 (17.9\%), 422 (43.7\%), and $370(38.3 \%)$ patients were categorized as having mild, moderate, and severe atrophic gastritis, respectively.

Non-DM patients who underwent eradication therapy were significantly younger than DM patients (60.7 and 64.8 years, respectively). The mean follow-up period (4.18 years for non-DM patients and 4.78 years for DM patients) and mean endoscopy interval (1.37 years for 
Table 1 Characteristics of patients with and without DM who underwent $H$. pylori eradication therapy

\begin{tabular}{|c|c|c|c|}
\hline Total $(n=965)$ & Non-DM $(n=447)$ & $\mathrm{DM}(n=518)$ & $p$ \\
\hline Mean age (range), years & $60.7(27-84)$ & $64.8(30-86)$ & $<0.0001^{*}$ \\
\hline Sex, $n(\%)$ & & & $<0.0001^{*}$ \\
\hline Female & $139(31.1 \%)$ & $97(18.7 \%)$ & \\
\hline Male & $308(68.9 \%)$ & $421(81.3 \%)$ & \\
\hline Mean follow-up period (range), years & $4.18(0.54-13.2)$ & $4.78(0.68-16.2)$ & $0.0006^{*}$ \\
\hline Mean endoscopy interval (range), years & $1.37(0.40-8.38)$ & $1.61(0.34-8.08)$ & $<0.0001^{*}$ \\
\hline Mean body mass index (range), kg/m² & $23.1(14.8-34.9)$ & $23.4(15.9-32.3)$ & 0.1452 \\
\hline Atrophic gastritis grade, $n(\%)$ & & & $0.0011^{*}$ \\
\hline Mild & $95(21.3 \%)$ & $78(15.1 \%)$ & \\
\hline Moderate & $207(46.3 \%)$ & $215(41.5 \%)$ & \\
\hline Severe & $145(32.4 \%)$ & $225(43.4 \%)$ & \\
\hline Hypertension, $n$ (\%) & 99 (22.1\%) & $244(47.1 \%)$ & $<0.0001^{*}$ \\
\hline Hyperlipidemia, $n$ (\%) & 89 (19.9\%) & $220(42.5 \%)$ & $<0.0001^{*}$ \\
\hline Hyperuricemia, n (\%) & $32(7.16 \%)$ & $48(9.27 \%)$ & 0.236 \\
\hline
\end{tabular}

DM diabetes mellitus

*Statistically significant $(p<0.05)$

non-DM patients and 1.61 years for DM patients) of the non-DM patients were significantly shorter than those of the DM patients. The mean BMI $\left(23.1 \mathrm{~kg} / \mathrm{m}^{2}\right.$ for non-DM patients and $23.4 \mathrm{~kg} / \mathrm{m}^{2}$ for DM patients) was not significantly different between non-DM and DM patients. The proportion of patients who received medications for HT and HL was higher in DM than in non-DM patients.

\section{Incidence and characteristics of gastric cancer after H. pylori eradication}

During the follow-up period, 21 gastric cancers [9 in non-DM patients $(0.482 \% /$ year $)$ and 12 in DM patients $(0.485 \%$ /year)] were diagnosed after $H$. pylori eradication (Table 2). No gastric cancer was found in the mild atrophic gastritis group, while 8 (38.1\%) gastric cancers were diagnosed in the moderate atrophic gastritis group and $13(61.9 \%)$ in the severe atrophic gastritis group. Among these 21 gastric cancers, there were no cardiac cancers. Eleven (52.4\%) gastric cancers had a depth of invasion limited to the mucosa; the remainder [10 (47.6\%)] exhibited submucosal or deeper invasion.

The mean age (69.4 years for non-DM patients and 70.6 years for DM patients), the proportion of males (77.8 \% for non-DM patients and $91.7 \%$ for DM patients), mean follow-up duration (4.59 years for non-DM patients and 3.95 years for DM patients), mean endoscopy interval (1.93 years for non-DM patients and 1.62 years for DM patients), mean BMI $\left(23.4 \mathrm{~kg} / \mathrm{m}^{2}\right.$ for non-DM patients and $22.6 \mathrm{~kg} / \mathrm{m}^{2}$ for DM patients) and atrophic gastritis grade were not significantly different between the gastric cancer patients with versus without DM.
In total, 16 (76.2 \%) intestinal-type gastric cancer and 5 (23.8\%) diffuse-type gastric cancer cases were diagnosed. Among the non-DM gastric cancer patients, $88.9 \%(8 / 9)$ were of the intestinal type, compared with $66.7 \%(8 / 12)$ of the DM gastric cancer patients. Regarding gastric cancer treatment modalities, 11 (52.4\%) patients underwent curative endoscopic treatment. The remaining 10 (47.6\%) patients received curative surgical treatment. There were no significant differences in the pathology, diameter $(22.1 \mathrm{~mm}$ for non-DM patients and $25.0 \mathrm{~mm}$ for DM patients), depth, location, or treatment of the gastric cancers between patients with and without DM.

Kaplan-Meier analysis of the proportions of patients free of gastric cancer after $H$. pylori eradication with and without DM is shown in Fig. 1. No significant difference was found in the incidence of gastric cancer after eradication between non-DM and DM patients by log-rank test $(p=0.8754)$.

Risk factors for gastric cancer after $H$. pylori eradication

We next analyzed the risk factors for gastric cancer after H. pylori eradication using Cox's proportional hazards model (Table 3). Age, sex, BMI, DM, HT, HL, and HU were not found to be risk factors for gastric cancer after $H$. pylori eradication in either univariate or multivariate analysis. Severe atrophic gastritis before eradication was identified as a significant risk factor for gastric cancer after $H$. pylori eradication in the multivariate analysis (OR 2.56, $95 \%$ CI 1.03-6.77, $p=0.0424$ ), in accordance with a previous report [9]. 
Table 2 Characteristics of gastric cancer in patients with and without DM after $H$. pylori eradication therapy

\begin{tabular}{|c|c|c|c|}
\hline Total $(n=21)$ & Non-DM $(n=9)$ & $\mathrm{DM}(n=12)$ & $p$ \\
\hline Mean age (range), years & $69.4(56-80)$ & $70.6(60-78)$ & 0.7137 \\
\hline Sex, $n(\%)$ & & & 0.5533 \\
\hline Female & $2(22.2 \%)$ & $1(8.33 \%)$ & \\
\hline Male & 7 (77.8 \%) & $11(91.7 \%)$ & \\
\hline Mean follow up period (range), years & $4.59(1.03-11.8)$ & $3.95(0.95-7.15)$ & 0.6990 \\
\hline Mean endoscopy interval (range), years & $1.93(0.99-4.06)$ & $1.62(0.70-2.95)$ & 0.2527 \\
\hline Mean body mass index (range), $\mathrm{kg} / \mathrm{m}^{2}$ & $23.4(19.5-27.5)$ & $22.6(19.0-30.1)$ & 0.5534 \\
\hline Atrophic gastritis, $n(\%)$ & & & 0.2030 \\
\hline Mild & 0 & 0 & \\
\hline Moderate & $5(55.6 \%)$ & $3(25.0 \%)$ & \\
\hline Severe & $4(44.4 \%)$ & $9(75.0 \%)$ & \\
\hline Pathology, $n(\%)$ & & & 0.3383 \\
\hline Intestinal type & $8(88.9 \%)$ & $8(66.7 \%)$ & \\
\hline Diffuse type & $1(11.1 \%)$ & $4(33.3 \%)$ & \\
\hline Diameter, mm & $22.1(3-70)$ & $25.0(5-60)$ & 0.7543 \\
\hline Depth, $n(\%)$ & & & 0.2562 \\
\hline Mucosa & $6(66.7 \%)$ & $5(41.7 \%)$ & \\
\hline Submucosa and deeper & $3(33.3 \%)$ & $7(58.3 \%)$ & \\
\hline Location, $n(\%)$ & & & 0.7332 \\
\hline Upper third & $3(33.3 \%)$ & $2(16.7 \%)$ & \\
\hline Middle third & $3(33.3 \%)$ & $5(41.7 \%)$ & \\
\hline Lower third & $3(33.3 \%)$ & $5(41.7 \%)$ & \\
\hline Treatment, $n(\%)$ & & & 0.3869 \\
\hline Endoscopic & $6(66.7 \%)$ & $5(41.7 \%)$ & \\
\hline Surgery & 3 (33.3 \%) & $7(58.3 \%)$ & \\
\hline
\end{tabular}

$D M$ diabetes mellitus

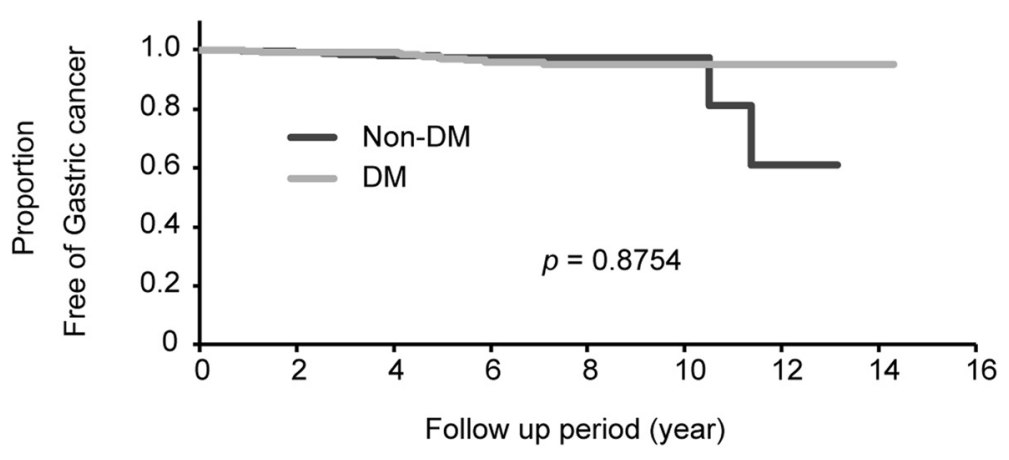

Number at risk

$\begin{array}{lllllllll}\text { Non-DM } & 447 & 309 & 198 & 100 & 28 & 7 & 2 & 0 \\ \text { DM } & 518 & 394 & 269 & 154 & 58 & 26 & 12 & 1\end{array}$

Fig. 1 Kaplan-Meier analysis of the proportion of patients with and without diabetes mellitus (DM) free from gastric cancer after $H$. pylori eradication therapy. Gastric cancer was diagnosed in nine non-DM patients and 12 DM patients during the follow-up period ( $p=0.8754$, log-rank test) 
Table 3 Cox's proportional hazards model for factors associated with the incidence of gastric cancer after $H$. pylori eradication

\begin{tabular}{|c|c|c|c|c|}
\hline \multirow[t]{2}{*}{ Factor } & Univariate & $p$ & Multivariate & $p$ \\
\hline & \multicolumn{2}{|l|}{ OR $(95 \%$ Cl) } & \multicolumn{2}{|l|}{ OR $(95 \% \mathrm{Cl})$} \\
\hline Age (years) & $1.01(0.96-1.06)$ & 0.6248 & $1.00(0.94-1.05)$ & 0.9446 \\
\hline \multicolumn{5}{|l|}{ Sex } \\
\hline Female & 1 & & & \\
\hline Male & $1.82(0.61-7.78)$ & 0.3030 & $2.13(0.67-9.46)$ & 0.1914 \\
\hline Body mass index $\mathrm{kg} / \mathrm{m} 2) \mathrm{m}^{2}$ ) & $1.02(0.83-1.13)$ & 0.7880 & $1.01(0.83-1.15)$ & 0.8264 \\
\hline \multicolumn{5}{|l|}{ Diabetes mellitus (DM) } \\
\hline Non-DM & 1 & & & \\
\hline DM & $0.93(0.39-2.30)$ & 0.8756 & $0.64(0.25-1.66)$ & 0.3530 \\
\hline \multicolumn{5}{|l|}{ Hypertension (HT) } \\
\hline Non-HT & 1 & & & \\
\hline $\mathrm{HT}$ & $1.40(0.57-3.31)$ & 0.4459 & $1.36(0.53-3.36)$ & 0.4985 \\
\hline \multicolumn{5}{|l|}{ Hyperlipidemia (HL) } \\
\hline Non-HL & 1 & & & \\
\hline $\mathrm{HL}$ & $1.15(0.43-2.83)$ & 0.7600 & $1.17(0.42-2.99)$ & 0.7485 \\
\hline \multicolumn{5}{|l|}{ Hyperuricemia (HU) } \\
\hline Non-HU & 1 & & & \\
\hline $\mathrm{HU}$ & $0.62(0.03-3.05)$ & 0.6295 & $0.43(0.02-2.24)$ & 0.3811 \\
\hline \multicolumn{5}{|l|}{ Atrophic gastritis } \\
\hline Mild-Moderate & 1 & & & \\
\hline Severe & $2.63(1.10-6.67)$ & $0.0280^{*}$ & $2.56(1.03-6.77)$ & $0.0424^{*}$ \\
\hline
\end{tabular}

$O R$ odds ratio; $\mathrm{Cl}$ confidence interval

* Statistically significant $(p<0.05)$

\section{Discussion}

In this study, we aimed to elucidate the incidence and characteristics of gastric cancer after $H$. pylori eradication therapy in DM patients. Our results indicated that the incidence and characteristics of gastric cancer developing after $H$. pylori eradication therapy were not significantly different between DM and non-DM patients. The incidence of gastric cancer after eradication was $0.48 \% /$ year and the mean age of the patients 62 years. The incidence and mean age are in agreement with those reported by Ogura et al. ( $0.46 \%$ /year and 62 years, respectively) [6]. Kamada et al. reported that severe mucosal atrophy in the corpus is a risk factor for gastric cancer after eradication [9]. This study also showed that severe atrophic gastritis before eradication is the risk for gastric cancer suggesting follow-up endoscopy of patients with severe atrophic gastritis is necessary.

The prevalence of DM is rapidly increasing, and several studies have focused on the interaction of DM with H. pylori infection and the gastric cancer axis [20-22]. The prevalence of $H$. pylori infection in DM patients is reportedly higher than that in non-DM patients [23]. Sekikawa et al. reported that open-type atrophic gastritis is found more frequently in DM patients than in nonDM patients (33.4 \% (50/148) and $21.1 \%$ (274/1301), respectively); moreover, the presence of DM increased the risk of development of early gastric cancer. In the present study, the presence of DM did not increase the incidence of gastric cancer after $H$. pylori eradication therapy. It is possible that DM acts synergistically with consistent $H$. pylori infection to increase the risk of gastric cancer, as reported previously [24], and that the presence of DM after $H$. pylori eradication therapy might not enhance the risk of gastric cancer.

Other possible risk factors for gastric cancer (such as smoking and high salt intake) have been reported to increase gastric cancer risk synergistically with $H$. pylori infection $[25,26]$. A prospective study conducted in Japan (the Hisayama study) found that the combination of smoking and $H$. pylori infection increased the risk of gastric cancer more than did smoking or $H$. pylori infection alone [25]. The Hisayama study also found a significant association between high salt intake and gastric cancer in a population with atrophic gastritis and H. pylori infection [26].

In the present study, the pathological features of gastric cancer after eradication were not significantly different between DM and non-DM patients. This finding is in line with a previous report that there is no significant difference in the histopathological differentiation of 
gastric cancer in patients with versus without DM [27]. The proportion of those with intestinal-type gastric cancer after eradication $(76.2 \%, 16 / 21)$ in this study is in agreement with that reported by Kamada et al. $(75.0 \%, 15 / 20)$ [9].

There were several limitations to our study. First, it was a retrospective cohort design; therefore, further prospective and longer-term studies are required. Second, several possible risk factors for gastric cancer-such as smoking, alcohol intake, dietary habits, family history and $H$. pylori virulence factors-were not evaluated. Regarding lifestyle factors, a previous report showed that smoking and drinking alcohol were not associated with the development of gastric cancer after $H$. pylori eradication therapy [28].

\section{Conclusion}

Our findings indicated that the incidence and characteristics of gastric cancer after $H$. pylori eradication therapy were comparable between DM and non-DM patients.

\section{Abbreviations}

DM: Diabetes mellitus.

\section{Competing interests}

The authors declare that they have no competing interests.

\section{Authors' contributions}

K Sakitani collected and analyzed the data, and drafted the manuscript. YH analyzed the data and revised the manuscript. NS, SS, TS, and YY analyzed the data. AY, K Sakamoto, MA, and SM collected and analyzed the data. YI, SK and KK supervised the study.

\section{Acknowledgements}

The authors thank the gastroenterologists who performed the endoscopic procedures and the diabetes specialists who managed the diabetes patients at the Institute for Adult Diseases, Asahi Life Foundation Hospital (Tokyo, Japan). We are grateful to $\mathrm{N}$. Tachibana and $\mathrm{Y}$. ligaya for their arrangement of the database.

\section{Author details}

'The Institute for Adult Diseases, Asahi Life Foundation, 2-2-6 Bakuro-cho, Nihon-Bashi, Chuo-ku, Tokyo 113-8655, Japan. ${ }^{2}$ Department of Gastroenterology, Graduate School of Medicine, The University of Tokyo, Tokyo, Japan. ${ }^{3}$ Gastroenterology Division, Yokohama City University Graduate School of Medicine, Yokohama, Japan.

Received: 20 August 2015 Accepted: 14 October 2015

Published online: 21 October 2015

\section{References}

1. Warren JR, Marshall BJ. Unidentified curved bacilli on gastric epithelium in active chronic gastritis. Lancet. 1983;1 (8336):1273-5.

2. Correa P. Human gastric carcinogenesis - a multistep and multifocul process - 1st American-Cancer-Society Award Lecture on cancer-epidemioplogy and prevention. Cancer Res. 1992;52(24):6735-40.

3. Uemura N, Okamoto S, Yamamoto S, Matsumura N, Yamaguchi S, Yamakido $\mathrm{M}$, et al. Helicobacter pylori infection and the development of gastric cancer. N Engl J Med. 2001;345(11):784-9.

4. Sakitani K, Hirata Y, Watabe H, Yamada A, Sugimoto T, Yamaji Y, et al. Gastric cancer risk according to the distribution of intestinal metaplasia and neutrophil infiltration. J Gastroenterol Hepatol. 2011;26(10):1570-5.

5. Shichijo S, Hirata Y, Sakitani K, Yamamoto S, Serizawa T, Niikura R, et al. The distribution of intestinal metaplasia as a predictor of gastric cancer development. J Gastroenterol Hepatol. 2015;30(8):1260-4.
6. Ogura K, Hirata Y, Yanai A, Shibata W, Ohmae T, Mitsuno Y, et al. The effect of Helicobacter pylori eradication on reducing the incidence of gastric cancer. J Clin Gastroenterol. 2008;42(3):279-83.

7. Fukase K, Kato M, Kikuchi S, Inoue K, Uemura N, Okamoto S, et al. Effect of eradication of Helicobacter pylori on incidence of metachronous gastric carcinoma after endoscopic resection of early gastric cancer: an open-label, randomised controlled trial. Lancet. 2008;372(9636):392-7.

8. Take S, Mizuno M, Ishiki K, Hamada F, Yoshida T, Yokota K, et al. Seventeenyear effects of eradicating Helicobacter pylori on the prevention of gastric cancer in patients with peptic ulcer; a prospective cohort study. J Gastroenterol. 2015;50(6):638-44.

9. Kamada T, Hata J, Sugiu K, Kusunoki H, Ito M, Tanaka S, et al. Clinical features of gastric cancer discovered after successful eradication of Helicobacter pylori: results from a 9-year prospective follow-up study in Japan. Aliment Pharmacol Ther. 2005;21(9):1121-6.

10. Yamamoto K, Kato M, Takahashi M, Haneda M, Shinada K, Nishida U, et al. Clinicopathological analysis of early-stage gastric cancers detected after successful eradication of Helicobacter pylori. Helicobacter. 2011;16(3):210-6.

11. Karin $M$, Lawrence $T$, Nizet $V$. Innate immunity gone awry: linking microbial infections to chronic inflammation and cancer. Cell. 2006;124(4):823-35.

12. Giovannucci E, Harlan DM, Archer MC, Bergenstal RM, Gapstur SM, Habel LA, et al. Diabetes and cancer: a consensus report. Diabetes Care. 2010;33(7):1674-85.

13. Hidaka A, Sasazuki S, Goto A, Sawada N, Shimazu T, Yamaji T, et al. Plasma insulin, C-peptide and blood glucose and the risk of gastric cancer: the Japan Public Health Center-based prospective study. Int J Cancer. 2015;136(6):1402-10.

14. Seino Y, Nanjo K, Tajima N, Kadowaki T, Kashiwagi A, Araki E, et al. Report of the committee on the classification and diagnostic criteria of diabetes mellitus. J Diabetes Investig. 2010;1(5):212-28.

15. Yanai A, Sakamoto K, Akanuma M, Ogura K, Maeda S. Non-bismuth quadruple therapy for first-line Helicobacter pylori eradication: a randomized study in Japan. World I Gastrointest Pharmacol Ther. 2012;3(1):1-6.

16. Hirata Y, Ohmae T, Yanai A, Sakitani K, Hayakawa Y, Yoshida S, et al, Sitafloxacin resistance in Helicobacter pylori isolates and sitafloxacin-based triple therapy as a third-line regimen in Japan. Int J Antimicrob Agents. 2012;39(4):352-5.

17. Kimura K, Takemoto T. an endoscopic recognition of the atrophic border and its significance in chronic gastritis. Endoscopy. 1969;1 (3):87-97.

18. Satoh K, Kimura K, Taniguchi Y, Yoshida Y, Kihira K, Takimoto T, et al. Distribution of inflammation and atrophy in the stomach of Helicobacter pylori-positive and -negative patients with chronic gastritis. Am J Gastroenterol. 1996;91(5):963-9.

19. Lauren P. The two histological main types of gastric carcinoma - diffuse and so-called intestinal-type carcinoma - an attempt at a histo-clinical classification. Acta Pathol Et Microbiol Scand. 1965;64(1):31-49.

20. Tseng $\mathrm{CH}$, Tseng FH. Diabetes and gastric cancer: the potential links. World J Gastroenterol. 2014;20(7):1701-11.

21. Tian T, Zhang LQ, Ma XH, Zhou JN, Shen J. Diabetes mellitus and incidence and mortality of gastric cancer: a meta-analysis. Exp Clin Endocrinol Diabetes. 2012;120(4):217-23.

22. Yoon JM, Son KY, Eom CS, Durrance D, Park SM. Pre-existing diabetes mellitus increases the risk of gastric cancer: a meta-analysis. World J Gastroenterol. 2013;19(6):936-45.

23. Zhou X, Zhang C, Wu J, Zhang G. Association between Helicobacter pylori infection and diabetes mellitus: a meta-analysis of observational studies. Diabetes Res Clin Pract. 2013;99(2):200-8.

24. Ikeda F, Doi Y, Yonemoto K, Ninomiya T, Kubo M, Shikata K, et al. Hyperglycemia increases risk of gastric cancer posed by Helicobacter pylori infection: a population-based cohort study. Gastroenterology. 2009;136(4):1234-41.

25. Shikata K, Doi Y, Yonemoto K, Arima H, Ninomiya T, Kubo M, et al. Population-based prospective study of the combined influence of cigarette smoking and Helicobacter pylori infection on gastric cancer incidence: the Hisayama Study. Am J Epidemiol. 2008;168(12):1409-15.

26. Shikata K, Kiyohara Y, Kubo M, Yonemoto K, Ninomiya T, Shirota T, et al. A prospective study of dietary salt intake and gastric cancer incidence in a defined Japanese population: the Hisayama study. Int I Cancer. 2006;119(1):196-201. 
27. Wei ZW, Li JL, Wu Y, Xia GK, Schwarz RE, He YL, et al. Impact of pre-existing type-2 diabetes on patient outcomes after radical resection for gastric cancer: a retrospective cohort study. Dig Dis Sci. 2014;59(5):1017-24.

28. Take S, Mizuno M, Ishiki K, Yoshida T, Ohara N, Yokota K, et al. The longterm risk of gastric cancer after the successful eradication of Helicobacter pylori. J Gastroenterol. 2011;46(3):318-24.

Submit your next manuscript to BioMed Central and take full advantage of:

- Convenient online submission

- Thorough peer review

- No space constraints or color figure charges

- Immediate publication on acceptance

- Inclusion in PubMed, CAS, Scopus and Google Scholar

- Research which is freely available for redistribution 